\title{
Teaching meditation to college students within an historical and cultural context: A qualitative analysis of undergraduate reflections on contemplative practice
}

\author{
Sylvia Sensiper ${ }^{1}$ (i) \\ Accepted: 27 January 2022 \\ (c) The Author(s) 2022
}

\begin{abstract}
There is a growing interest in contemplative practices in higher education. Researchers have explored the use of meditation to address the increasing requests for counseling and as a resource for improving student mental health. Contemplative practices have also been incorporated into the fundamental learning objectives in some US universities. This study of teaching methods uses first-person narratives from twenty-three 10-week seminars to examine how meditation practice benefited undergraduate students at a large public university in the US. The seminar, "Contemporary American Buddhism: How Meditation Became a Part of the Mainstream," provided meditation instruction within an historical and cultural context and was taught over a nine-year period. Four hundred undergraduates' reflective writings were included in this study. During the seminars, students participated in structured in-class meditations, practiced mindfulness exercises, read contemporary texts, viewed recent media and wrote reflective exercises. Students learned how meditation has been adapted for contemporary society, engaged in critical thinking, and reflected on their experiences. An examination of their narrative self-reports indicates outcomes similar to studies using highly structured meditation protocols; an improvement in overall well-being, lessened anxiety, better focus and increased emotional control. This study of teaching methodology also shows that students expressed a desire to continue the practice once the seminar was complete. The results suggest that a structured and systematic investigation of this teaching model would add significantly to the discussion on how to teach contemplative practice to college students.
\end{abstract}

Keywords Meditation $\cdot$ Contemplative practices $\cdot$ Mental health $\cdot$ Mindfulness $\cdot$ Undergraduates

\section{Introduction}

The core practices of Buddhist meditation have become increasingly available in many areas of contemporary life. Meditation instruction is offered in corporations, K-12 schools, and prisons, while popular books and teaching systems have flourished. Often recommended by psychologists and other healthcare providers as a way to enhance wellbeing, a growing body of research indicates that meditation practice can improve emotional control and reduce and alleviate distressing health conditions including chronic pain, depression and anxiety (Astin, 1997; Baer, 2003; Brown et al., 2007; Kabat-Zinn, 1982; la Cour \& Petersen, 2015;

Sylvia Sensiper

ssensiper@ucdavis.edu

1 Department of Anthropology, UC Davis, 1615 Navajo Street, Davis, CA 95616, USA
Würtzen et al., 2013; Bamber \& Schneider, 2016). Additional studies have shown meditation to enhance empathy (Beddoe \& Murphy, 2004); expand self-awareness (van der Riet et al., 2014); increase compassion and social understanding (Scida \& Jones, 2017); improve attentional processing (van den Hurk et al., 2010); and boost information retention (Ramsburg \& Youmans, 2014). Given this validation from the scientific community, there have been efforts to incorporate meditation practice into higher education, an innovation that generally follows one of two developments. The first endeavor seeks to address the growing mental health concerns on university campuses and focuses on meditation as an antidote to stress. ${ }^{1}$ The other acknowledges

\footnotetext{
1 The annual report from the Center for Collegiate Mental Health reported that during the period between 2009 and 2015, counseling center utilization increased by an average of $30-40 \%$, while enrollment increased by only 5\%. (Center for Collegiate Mental Health, 2018. 2017 Annual Report)
} 
meditation as a contemplative practice, one that allows students to deeply investigate a critical first-person perspective, cultivate well-being and explore purpose and values (Bush, 2011; Britton et al., 2013).

Citing the research on meditation's benefits, many educators and researchers have considered the practice as a way to address the increasing number of requests for counseling and mental health services through serving multiple students at once. These academics have created stand-alone instructional units or included meditative practice into an existing class, structuring these interventions as a dual project that provides training to students in the practice itself and an investigation of its effectiveness. In general, these types of studies use Mindfulness Based Stress Reduction (MBSR), a meditation program developed by Jon Kabat-Zinn at the University of Massachusetts Amherst to help patients deal with chronic pain. As originally designed, MBSR is a systematic 8-week group format practice that explores the mind/ body connection and offers effective methods for facing and relieving suffering (Kabat-Zinn, 2003). ${ }^{2}$ Participants meet weekly for 2.5-hour group sessions in addition to one 6-hour day-long retreat, for a total of 26 contact hours. Research examining the effectiveness of MBSR and the various adaptations of its methods has grown significantly. This increase is demonstrated by a PubMed search that found "mindfulness" mentioned in only eleven articles published between 1980 and 1989, but citations in 2,263 articles between 2011 and August 2015 (Ching et al., 2015).

Although a number of classroom studies incorporate the full eight-week MBSR curriculum (Malpass et al., 2019), more often it is determined to be too time-consuming for busy undergraduates. Instead, research is aimed at finding the most concise type of presentation and the shortest 'dosage' that will be effective. Various investigations at different universities have adapted MBSR to a six-week course (Canby et al., 2015; Newsome et al., 2012; Ingram et al., 2017), a five-week course (Bergen-Cico et al., 2013), a three-week course (Parcover et al., 2018), and a two-week online course (Cavanagh et al., 2013). Other scholars have designed and researched a course of four consecutive days (Short et al., 2015), integrated short periods of three to five minutes of a mindfulness intervention each week during class (Schwind, et al., 2016; Miller et al., 2018), and examined the use of informal versus formal meditation instruction (Hindman et al., 2015). These studies generally

\footnotetext{
2 MBSR draws on the teachings of the Buddha but was intentionally created to be free of ideological, cultural and religious ideas associated with Buddhism, while still remaining faithful to the universe of ideas to which mindfulness alludes. Kabat-Zinn refers to the teachings of the Buddha, the Dharma, as "a coherent phenomenological description of the nature of mind, emotion, and suffering and its potential release." (Kabat-Zinn, 2003).
}

employ specially designed mindfulness scales such as the Mindfulness Attention Awareness Scale (Brown \& Ryan, 2003) or the Kentucky Inventory of Mindfulness Skills (KIMS), (Baer et al., 2004). ${ }^{3}$ These are used in conjunction with mental health instruments or other questionnaires that address the issues under investigation. For example, in a study to determine if a group mindfulness intervention could be an efficient alternative to one-on-one counseling dealing with depression and anxiety, researchers used the Five Facet Mindfulness Questionnaire (FFMQ) in conjunction with DASS-21, a short-form scale derived from the Depression Anxiety Stress Scales (DASS) (Parcover et al., 2018).

Meditation has also been integrated into higher education through focusing on the contemplative aspect of the practice and making it fundamental to the learning and disciplinary goals of the university. This is most evident in the nascent field of Contemplative Science or Contemplative Studies. Various initiatives have been established at different campuses and class offerings may include MBSR and other meditation practices, as well as yoga, tai chi and self-inquiry. These initiatives are generally interdisciplinary and engage in research projects and endeavors across the campus and in the community. The University of Virginia's Contemplative Science Center offers a curriculum that includes courses on the Art and Science of Human Flourishing and Mindfulness in Nature, but is also a pan-university venture that collaborates with departments and schools across the campus in an on-going cultural shift towards a more contemplative and compassionate university (Trail \& Cunningham, 2018). For example, the School of Architecture is studying how the built environment can positively impact mental, social and emotional states and has also developed a network of contemplative spaces on campus; the School of Nursing offers an MBSR course, a course in Tibetan medicine, and is home to an on-going group of research projects investigating mind-body practices; and in the School of Education, research projects investigate how best to integrate contemplative practices for the benefit of both $\mathrm{K}-12$ students and teachers. ${ }^{4}$ At Brown University the Contemplative Studies Initiative brings together students and faculty across the disciplines through the development of an "Integrative Contemplative Pedagogy" that seeks to enhance attentional focus, emotional intelligence, self-awareness, and balance a traditional 'third-person' perspective with a critical first-person perspective. The university's Alpert School of Medicine offers the Scholarly Concentrations Program which allows

\footnotetext{
For a discussion of five commonly used mindfulness scales see Using Self Report Methods to Assess Mindfulness, (Baer et al., 2006).

4 See https://csc.virginia.edu/.
} 
medical students to integrate contemplative studies into their traditional curriculum. ${ }^{5}$ At other universities, individual educators have designed classes integrating contemplative practice into diverse disciplines including management (Culham, 2013), law (Riskin, 2012), and math (Wolcott, 2013), among others. ${ }^{6}$

Within this broad landscape of contemplative practice in higher education, this paper provides a retrospective analysis of a series of anthropologically-oriented first-year seminars that provided meditation instruction to undergraduate students at a large public university in the U.S. over a nineyear period. The class, "Contemporary American Buddhism: How Meditation Became a Part of the Mainstream," directly addressed the history of meditation and its cultural contexts while providing instruction and time for practice. The student reflection papers and online responses to mindfulness exercises served as the qualitative resource for an examination of the teaching methodology utilized and the impact on course participants.

Davidson and Kazniak (2015) have surveyed the methodological and conceptual issues involved in research on meditation and emphasized the need for a rich description of the intervention and specifics about the pedagogy employed. This analysis of teaching methods provides these details and is structured in the following way: the first two sections describe the creation of the class and an overview of the basic components of the curriculum. Included are descriptions of the meditations practiced and the training and background of the instructor. The subsequent section details the methods used to analyze the ethnographic texts and student self-reports. This is followed by a qualitative assessment of the students' experiences. The analysis indicates an improvement in overall well-being with some students reporting experiences more traditionally associated with meditation practiced in a spiritual context. The discussion section concludes with suggestions for systematic research on the usefulness of this curriculum and teaching model.

\section{Background and Class Development}

Contemporary American Buddhism was designed to be a part of the First Year Seminars at a large public university in

\footnotetext{
5 Additional universities and colleges that have developed contemplative curriculums include Oregon State University Contemplative Studies Initiative (CSI), Contemplative Education at Naropa University, Contemplative Education at the University of Redlands, Contemplative Studies at Emory and Rice Universities, and Creativity and Consciousness Studies at University of Michigan.

6 From 1997 to 2009, The Center for Contemplative Mind in Society provided support for scholars and academics to integrate contemplative practice into their academic teaching, often through participation in the Center's Contemplative Practice Fellowship program. https:// www.contemplativemind.org/about/history.
}

the U.S., a program of small classes that introduce students to the fundamentals of scholarship at a research university and help them develop critical thinking skills. ${ }^{7}$ The courses also promote a sense of belonging for the approximately six thousand new students who enter the university annually. Freshmen live together in campus dormitories for their incoming year, but academic learning is mostly impersonal. During their first quarters of instruction, students are introduced to their majors through large courses that generally include 100 to 500 peers with discussion sections led by graduate students. In contrast, the first-year seminars have an enrollment limit of nineteen and the small class size allows students to have closer interactions with classmates and instructors. They are taught by faculty and other teaching staff who often take this opportunity to explore an intellectual interest outside of their regular research projects.

Within this context, Contemporary American Buddhism was originally conceived as an anthropological investigation of modern-day practices. The class explored how meditation had been re-imagined to deal with present day concerns, as well as the manner in which it had been "medicalized" and scrutinized by researchers. After the first couple of quarters, however, the instructor modified the seminar, keeping the original intent as the overarching framework, and including additional in-class meditation as well as immersive field experiences, movies, self-experimentation and experiential exercises. This decision was a response to student's experience and feedback, and informed by the instructor's own background in meditation practice and knowledge of contemporary Buddhism.

In their personal introductions during the first week of class, the most common reason students stated for enrolling in the class was a desire to manage stress or anxiety. Many undergraduates are looking for ways to deal with the incessant pressure they feel within the context of a large bureaucracy that tests them frequently. Students have a brief 10 weeks during the quarter system to master the material in their various classes. Freshmen are often overwhelmed by the complexities of adjusting to life away from home, making new friends and all the developmental challenges of living on their own.

Meditation's reputation as a stress reliever has grown in the public's awareness and instruction is readily available in a variety of venues. As a result, many students came to class with some experience. They may have downloaded a

\footnotetext{
The institution serves approximately 30,000 undergraduates, representing the cultural diversity found in California: $22 \%$ are Hispanic, 33\% are Asian/Pacific Islander, 25\% are White, $4 \%$ are African American, $1 \%$ are Native American and for the remaining 2\%, race or ethnicity is unknown. International students make up $14 \%$ of the students and $59 \%$ are female and $41 \%$ are male (https://www.ucdavis. edu/sites/default/files/upload/files/uc-davis-student-profile.pdf).
} 
meditation app to their iPhone, watched a Youtube video or practiced silent meditation with their high school athletic team. In most of these situations, however, meditation had been provided as a 'technique.' Students thought they should practice only when they felt anxious or stressed and often had a common misconception that they were supposed to 'clear their mind.' They also had a limited understanding of their experiences beyond the idea that meditation was supposed to help them relax. Many students shared that they found it difficult to sustain their interest in a continued practice.

Offering the class from an anthropological perspective provided a way to help students with their immediate concerns and feelings of overwhelm, yet also allowed explorations that were particular to various individual interests. The curriculum offered students who had grown up in Buddhist households an explanation of why meditation may not be a part of their home life. Students whose family origins were in Asia or Southeast Asia often explained that their religious involvement included attending temple and celebrating rituals and holidays, yet meditation was usually the work of monastics. The class added a contemporary dimension to their understanding of their family religion, often referred to as 'heritage traditions' in the scholarly literature (Gleig, 2019). For students who pointed to a parent's meditation practice as their motivation, the class provided an explanation of the growth of "meditation-based convert lineages" (Gleig, 2019). Other students enrolled in the class with an ethical or spiritual motivation, and the readings and films allowed them to access the depth and breadth of contemplative practice and the history of the Buddhist tradition. In addition, students were made aware of experiences they might encounter with continuing practice as well as information about meditation centers and other organizations where they might go to find further education or involve themselves in a community. Overall, the course engaged students' varied interests and offered contexts within which to situate meditation as more than a technique.

\section{Class Structure}

The class was designed to provide meditation instruction, awareness exercises and readings and media presentations that contextualized the practice within an overarching framework of cultural change. Traditional Buddhist ideas were presented along with their current interpretations and students were challenged to think critically about contemplative practice.

In the seminar's first two classes the instructor introduced the main theme of the course through presenting a brief recounting of Siddhartha Gautama's life and the idea of 'Buddhist modernism' (McMahan, 2008). The second class presented the history of 'stress' (Selye, 1984), early studies on meditation, and the continuing scientific research that has investigated the practice as an antidote to this contemporary ailment. Subsequent classes focused on the traditional Buddhist teachings of the Four Noble Truths and the Eight-Fold Path, cultural traditions and communities in the U.S., how Western psychology has integrated Buddhist ideas, organizational dynamics in Buddhist centers, and research on difficult experiences in meditation (Lindahl et al., 2017). Students read contemporary Buddhist essays and viewed two documentaries; The Dhamma Brothers (Phillips et al., 2007) features a meditation program in an Alabama prison, and Unmistaken Child (Baratz, 2009) follows a Tibetan monk as he searches for his reincarnated master. The class also visited a local Tibetan Buddhist center. Each class meeting included discussion of the presented material and reserved time for fifteen to twenty minutes of silent meditation.

Mindfulness of the breath (shamatha) was introduced in the first class and students were encouraged to develop a regular practice. To help foster this new habit, they were required to submit meditation logs for the first two weeks documenting five minutes of daily meditation. Considered a 'focused attention' (FA) meditation in the scientific literature, shamatha helps the practitioner stabilize the mind by cultivating the ability to stay with the object of meditation, in this case the breath. At the midpoint of the class, the students were taught vipassana (insight), often referred to as an 'open monitoring' (OM) meditation, a practice in which the practitioner's attention opens to any phenomenon that is arising in their experience. To assist students, the instructor conducted guided meditations during class that focused on the Four Foundations of Mindfulness. Students reviewed translations of both the Anapanasati and Sattipathana sutras, the traditional teachings for both shamatha and vipassana, respectively, and compared them with definitions of FA and OM meditations in a published journal article to help understand contemporary adaptations (Lutz et al., 2008). Metta or loving-kindness meditation was also introduced at the class midpoint. This meditation is practiced by repeating a phrase or series of phrases that cultivates kindness. One of the goals of this contextual approach to meditation was to provide students with ways to think carefully about their own paths to taking the class and avenues they might pursue once the quarter was over.

In addition to their daily meditation practice, students were responsible for a number of written assignments; two reflection papers about their meditation experience, online posts in response to at-home awareness exercises, a short research exercise, a summary of their trip to the Tibetan Buddhist center and an answer to the question posed by the syllabus, what is meditation? These provided the instructor with insight into student practice and also helped students become more conscious of aspects of meditation they may have overlooked. Researchers have noted that inquiring 
about a meditator's experiences allows them to reflect and become aware of what may have escaped their attention, a process that helps them to refine and deepen their practice (Petitmengin et al., 2017).

To successfully pass the seminar, students had to complete all of the assignments and were only allowed one excused class absence. If they did miss a class, they were required to listen to a podcast on an aspect of Buddhist teaching from a list provided by the instructor and write a summary.

Over the course of the nine years, there were two students who had difficulties with the meditations in general. One student had a long-standing depression disorder and the other student had recently suffered a concussion in a car accident. The instructor worked with both students to find individualized solutions so that they could complete the classwork and benefit from the seminar. These student's struggles, and the more recent publications on difficult experiences in meditation, was what prompted the instructor to proactively include readings addressing this research to make students aware of possible issues that might arise.

The class pedagogy was based on the multi-sited fieldwork the instructor conducted for a Masters in visual anthropology at the University of Southern California. She also holds a $\mathrm{PhD}$ in public policy and social research from UCLA. The instructor has over thirty years of meditation practice and has attended retreats in the Tibetan, Zen and Therevada traditions, as well as in the Advaita tradition.

\section{Methods}

This retrospective analysis covers a period of nine years in which the class was taught every quarter to a total of 400 students. Students were between the ages of 18-25 with a few outliers of older students ranging in age up to 50 years. ${ }^{8}$ The qualitative analysis uses the written material the students produced during the class. The two reflection papers, one written in the second week of class and one in the ninth week, asked students to describe their meditation experience in general, taking into account the practice they did in class with their peers and the instructor, as well as their at-home practice. The prompts for these reflections included; "How does meditation feel? Is it easy or hard for you? Did you find any experiences outside of meditation that you attribute to your practice?" The suggested length for the reflection papers was 1-2 pages with an emphasis on student's description of experience. These papers were commented on by the instructor with additional pointers on how to practice and

8 Students 25 years and older make up $6 \%$ of the student population at this large public university. also informed class meditation instruction. Students additionally posted responses of 250 words or more to five different awareness exercises to the class website. The instructions asked students to directly reflect on whether the greater attention and focus during each exercise allowed them to become aware of something they hadn't noticed before. The final assignment was for students to answer the central question posed by the syllabus, "what is meditation?" and to articulate their own understandings.

The analysis employs a modified grounded theory approach often used in anthropology and policy analysis (Glaser \& Strauss, 1967; Clarke, 2005). This method is limited in its reliance on reported experience yet allows for similar statements to be located across subjects and aggregated into thematic groupings. The author read and annotated each student paper and posting, identifying specific concerns and types of varieties of experiences. Once each assignment was notated, the author further arranged these concerns into clusters of five major themes that highlighted student experiences. The language chosen for these larger themes emerged from students' concerns and also aligns with research that has been conducted on meditation in higher education. All of the assignments were considered in the construction of the themes but the reflection papers contained the more insightful comments, particularly the second papers that were written after students had been engaged in meditation for a number of weeks. In fact, for some students it wasn't until the end of class that they came to understand the subtly of the practice, a time factor that isn't reflected in the quotes used. It should be acknowledged that the vocabulary provided to the students may have shaped, to some degree, how they described their experiences when asked to do so. The questions themselves were open-ended, yet students were influenced by the readings on meditation and its effects, and may have been predisposed to respond similarly.

The themes are presented discretely for the purpose of clarity, yet the quotes are inextricably linked and often overlap due to their extraction from the broader responses. They were chosen to demonstrate the diversity and specificity of student experiences, an individuality that is lost in survey approaches to mindfulness research. Most student comments claimed very general benefits, and the quotes used in the thematic discussion are those that articulated the specifics of how the meditation practices had been helpful.

The five themes include: an improvement of overall wellbeing; increased emotional control; better concentration and ability to focus; increased awareness, joy and openness; and meditation can mean many things and that's okay.

\section{Presentation of Student Insights and Reflections}

In general, students' first reflection papers indicated their difficulties with finding time to meditate, their problems 
with the practice itself or the ways in which they had misunderstood the instructions for the practice of mindfulness of breath (shamatha). "I mean all you do is sit there and have a battle with your mind," wrote one student, "trying to clear your mind and thinking of absolutely nothing." Another student noted a popular book in which meditation plays a role and compared her practice. "[Much of the time] meditation becomes an interior fight with myself... It makes me feel like Liz Gilbert in Eat, Pray, Love..." Other students described previous learning experiences and their confusion about how to work with thoughts and problems with the practice. "In the past I have tried to learn to meditate on my own and I found it hard to close my mind to thoughts." Yet some students had an immediate calming response to the practice. "On the first day of class I was really stressed until we started meditating... [and then] I felt rejuvenated once we were done," wrote one student. Another noted the benefits of having live meditation instruction rather than a video or iPhone audio. "The guiding voice of an instructor is very soothing and peaceful for a beginner."

Despite the misunderstandings and difficulties at the beginning of the class, by the end of the quarter students had become much more discerning about the minds tendency to perpetuate thinking and wrote in their second reflection papers how they had become comfortable with the process. "My thoughts still wander, but I become conscious of it more quickly," wrote one student. "By practicing more frequently, I am able to identify when my mind is wandering and then simply let the thoughts go." Another noted that she had seen a marked improvement. "I have, gradually, gained the ability to let thoughts come and go with ease throughout my sitting meditation periods." As students found increased stability, there was a concurrent shift in attitude and habits, and their second reflection papers indicated these changes.

The teaching methodology used with the seminar was very different than the structured research projects teaching meditation to college students and young adults but the student reflections are consistent with those research results. Recent studies have shown a decrease in anxiety and stress (Bamber \& Schneider, 2016); significantly reduced psychological distress (Canby et al., 2015); and enhancements in positive emotionality and fewer episodes of mind wandering (Miller et al., 2018). The student reflections are also consistent with research that has shown a relationship between meditation and spiritual growth (Carmody et al., 2008; Gockel \& Deng, 2016).

\section{An Improvement of Overall Well-being}

Many students wrote in their second reflection papers that meditation had a positive and wide-ranging effect on their daily activities. "Ever since meditation was introduced into my life, I have grown a deeper and deeper appreciation for this technique of quieting the mind, clearing out all the negative clutter running around and becoming more aware and understanding," one student wrote. Another noted that “... [Practicing] meditation has made it that much easier to handle...everything from relationships, stress, school and my general health." And a number of students connected this increasing ease in their lives to an ability to be more energetic in getting things done, as well as an increasing comfort with the outcomes.

My decision to experiment with meditation is a major part of this new stage in my life... for the most part, my meditation practice has been extremely positive and rewarding as I feel like a happier, more productive person.

I have become more positive because I realize I don't have control over everything and I don't need to react to everything. Sometimes life just has to flow its own way.

Regular meditation helps bring awareness to a person's habitual thoughts and reactions and allows one to naturally find other ways of being and responding. Some students described their more relaxed persona and how this allowed them to be more attentive to their activities.

For once I'm not out of control but a calmer person. I'm the type of person who likes to do things without thinking about the future consequences. Maybe that's why for me, in life, I've made so many mistakes. But now I actually do think or step back and breath for a little.

Instead of cooking fast so I could turn on the television and watch something while I eat, or trying to eat something quickly so I could move on to the next activity, I have learned to pay attention to how I cook and eat. By paying attention to every bite of my food and listening to music not as a companion when doing homework but really listening to each beat of the drum...I started to appreciate the things I easily ignored.

For other students, the practice allowed them to simply make time for themselves which they often put aside because of the busyness of their lives. "As a college student I often forget how important it is to allow my mind the time to relax, which is why I can see the apparent benefits of meditation," one student wrote. "It takes my mind to a calmer place where I can just slip into a state of peacefulness effortlessly."

This increasing composure can help many students when they face difficult choices about their future. Undergraduates are changing rapidly and often are anxious about decisions. One student described some necessary changes she had to make and noted that meditation played an important role in the process. 
This quarter has really been a struggle for me...I had to learn to let go of certain expectations that others had set upon me, as well as the even higher expectations I had set upon myself. I had to realize and understand that I will never be the best and that I may never be "successful" in my artistry. I had to let go of the impossible hopes that I'd somehow make my way into galleries and museums without ever being a starving, struggling amateur. I had to let go of people who were a toxic influence in my life. I had to let go of my anger and my grudges, because honestly, they were holding me back emotionally and psychologically. I had numerous things I had to face and let go, and meditation has played a huge part in this.

In general, students wrote that their meditation practice helped them stabilize their thoughts and relieved them of some of the anxious churning rumination that occurs during the highly pressurized quarter. Once students found that meditation could be of help, they were more inclined to continue the practice, as noted by this student's reflection. "[Meditation] is something that I now feel important to do because of the positive effects it has on my day, and, more importantly, my attitude."

\section{Increased Emotional Control}

Emotional intelligence is an important skill when strong emotions arise, especially in new surroundings (Parker et al., 2004). Students often commented in their final reflections that they now experienced a greater acceptance of their emotions and found they were less irritated by things that had previously seemed abrasive. "I felt better because I was able to accept my emotions for what they are and embrace them [and that] brought me peace... I like that when I'm meditating, things that were bothering me don't seem to have any effect on me anymore." Another student noted that her attitude towards others was shifting. "I realized I was very judgmental of people and then judgmental of myself for being judgmental," she observed. "This was a big realization for me, and I now am working on being kind and understanding to all people."

Other students reported that meditation had strengthened their ability to handle difficult interpersonal situations and minimize the dramas of interaction.

I was very angry about two weeks ago about something. I decided instead of just feeling angry about it or moping around, to meditate instead. It really made me feel a lot better. I also felt a lot calmer and friendlier when confronting the person for making me upset. Every time I have practiced mindfulness of emotions, I end up being very grateful that I was able to grasp my attitude and prevent it from spiraling into something more and causing unnecessary turmoil within myself and those around me.

Students also reported relief from the daily tensions that might prompt a visit to the university counseling offices. "I have found meditation to be an effective tool to handle the unavoidable stresses that enter my life," noted one student. Another wrote, "I realized there is a lot of beauty and joy in seemingly insignificant things that are overlooked when one is overcome with negative emotions." And for students who experienced a high level of anxiety or distress, meditation appeared to be life-changing.

I have noticed that I don't suffer from panic attacks as often as I used to. I would freak out about certain things once every two weeks and now I feel happy and I believe that meditation is the best medicine for my anxiety...Meditating has helped me find myself and has helped me relax and not take things too seriously. I seem to have become more engaged and relaxed with constant daily work. In class I focus with great attention and don't play with my phone anymore. I've had no breakdowns this quarter and less anxiety as well... honestly, meditation has helped me get through this quarter.

The calming effect of shamatha helped students to become aware of their emotional responses and many also benefited from the more structured 'mindfulness of emotions' exercise that was one of the awareness exercises they were assigned as homework. Students were asked to attend to any given emotion as soon as it arose, and then pay close attention as it shifted and changed. The importance of this exercise was noted in the following comments below.

When I first started to feel distressed, I noticed how quickly the feeling was building up inside of me. The feeling then turned into anger and it stayed that way for a quick second. After feeling angry, I watched my emotion turn into sadness and then slowly into acceptance. I have never experienced my emotions one by one like that. It helped me realize sooner that the emotion would eventually pass.

Another student noted that the way she handled herself in social situations and relationships had changed. "I feel like some of the issues I've been facing (especially the social/ emotional issues), I have been able to approach...with a clearer mind, allowing for more maturity to rule my decisions rather than what is easy." In general, students found that meditation practice decreased the intensity of their feelings and allowed them to manage their emotional lives and their interpersonal situations more reasonably and responsibly. 


\section{Better Concentration and Ability to Focus}

Students reported towards the end of class that meditation impacted their ability to apply themselves to their academic studies in a number of ways. One student wrote that the class itself left her feeling better able to pay attention in her subsequent lecture. "I have found that I am really refreshed when I leave [meditation] class and I can concentrate more in the course I have next." Other students described how they had incorporated meditation into their school days and regular study routines.

... [at] times I just sat quietly in front of my desk and meditated as a break while studying and doing homework. It helps me concentrate better on the work.

Before I learned to meditate, if I had a crazy, busy day ahead of me, I would be super stressed out...After learning how to meditate, I try meditating throughout the day when I feel the most stressed. This not only helps me to re-focus my mind on the current task at hand, but also calms me and reassures me that everything will be okay.

One student drew a direct connection between his practice of meditation and his ability to avoid distractions and apply himself to his current project. "Personally, the greatest benefit I have received from meditation has been my increased ability to concentrate," he wrote. "It has become easier to notice when my thoughts change, and I am quick to expel other thoughts besides the assignment I'm working on." And another attributed his academic success to his greater capacity to focus.

I have found that it has really improved many aspects of my everyday life. I am doing much better academically because meditation has really helped me focus my mind on the task at hand.

Overall, students reported that meditation improved their ability to pay attention and study with more motivation. They found that their classes seemed more manageable and they were doing better academically.

\section{Increased Awareness, Joy and Openness}

At the beginning of the seminar, many students would mention 'managing stress' as their primary reason for taking the class, but there were also many who revealed a spiritual focus or an interest in Buddhist practice as a way to better understand themselves. No matter what a student's initial rationale for enrolling, many found their meditation experiences to be revitalizing and wrote about this in their second reflection or in answer to the final assignment addressing the questions 'what is meditation?'
"The feeling I get during meditation," reflected one student, "is a sense of increased awareness of the mind and body as well as a deep blissful, relaxed feeling afterwards." Another student noted the way in which the practice brought a sense of joy to her general orientation. "I really couldn't remember the last time I experienced such a relaxed feeling or moment," she wrote. "The feeling was so great that it just made me really happy." And another expressed her experience as an increase in openness and energetic optimism.

I have a bit of bounce in my step and a smile in my heart. I've never been this inspired or excited about being alive.

Many students described a broadened awareness and deeper sensitivity. "I have noticed a more profound awareness in almost everything I do," wrote one student, "whether I am talking to a friend, eating a bowl of cereal or taking a walk." Another student noted the connection between her meditation practice and the class discussions. She also reported that the positive internal changes she experienced were apparent to others.

I have noticed a difference in my outlook and personality... The specific word someone used was 'chipper'. After having meditated and [paid] attention to the things that we've been talking about in class, it is a lot easier to look at things more openly and many times in a positive light.

Students also noted a greater openness to the world at large. "Meditation is really relaxing and leaves me feeling at ease with life," wrote one student. "I always end up wanting to be peaceful and feel like the world is a good place." Another student noted a heightened connection to the natural world and an increased sensorial vividness, particularly after attending class.

I find that as I am leaving I have a much more grounded and comfortable feeling running through my body...I feel my feet hitting the uneven pavement. I hear the rustling of the trees and their leaves as they shade me from the sun. It is really a wonderful feeling, not only because of the awareness I have of my body, but also because of the awareness I have of the world around me. I can faintly feel the common connection that everything and everyone has with each other and it is a very comforting and peaceful realization.

Generally, students expressed an increased sense of ease and a greater awareness both of themselves and others. A number of students reported that they had shared their meditation practice with roommates, friends and family. 


\section{Meditation Means Many Things and That's Okay}

Most students stated that their concept of meditation changed over the course of the ten weeks and that their understanding expanded to include a range of practices and cultures. This was clear in their answers to the question - "what is meditation?" - which was their final assignment. "[Meditation] is a multitude of things that improves one's well-being as a whole," wrote one student. "Meditation is a way of life and is a different experience for everyone who encounters it," wrote another. In answering the question, most students defined the practice as a reliever of stress, a way to relax and a way to be more present in life, and then added specific and personal details. The responses were as individual as the students themselves.

Establishing a meditation practice has been liberating. It has given me a lot of insight into who I am. Who I am as a human being, a student, a friend, a sister, a daughter. Meditation has provided me with a narrow focus on how the activities I engage in relate to how I feel. It also allows me to free myself of experiencing emotions or feelings in a painful way. It has slowed down time for me, granting me a feeling of calm. I feel all the exercises we have learned and practiced are extremely productive in bringing me back to right now. They wake me up to what is happening in my body, my mind, my heart right now...For me, meditation is being alive to the moment right now.

Although I have always considered myself fairly secular, meditation has shined light on a spiritual side of me that I never imagined. Some of the recurring themes in Buddhism... have shown me how much work our internal selves demand from us in order to grow prosperously. I now acknowledge the complex life and interactions that surround me and make up the world I live in. I used to be quite self-centered, so I can say that meditation has truly humbled me, to say the least.

Meditation is what fuels my productivity. It is where inspiration comes for music, dreams, hopes, and awe. It is the magical land that lifts me up into the clouds while simultaneously making me feel balanced as my roots bury deep and hold me strongly. It is where I find motivation to continue writing, playing music, creating art, or anything else my heart desires. It is where I find ideas of what will fulfill my life. It is the place where I constantly discover the reason I'm present here at this very moment in time, the purpose I serve the universe, the people around me, and ultimately myself. Meditation is how I discover myself and the universe. In the physical sense, meditation is, yes, a stress relief. For me, the spiritual practice initially meant reducing anxiety. As I learned more about the history of Buddhism and the fact that enlightenment isn't just something exclusively for the more practiced, I find myself using meditation in everyday life. When I visited the [Tibetan Buddhist] center they fed me breakfast. I wondered why they took the time and money every morning to do so. They told me that the entire purpose of meditation was to be able to apply it to their daily lives. And that they did.

In their final reflection papers and in the last assignment, many students also articulated an aspiration to continue practicing.

I really think I should continue meditating after this class is over because during this last round of midterms, many people were stressing, but I feel much less stressed now, if at all. It helps me focus and not feel overwhelmed. I also just feel more connected to myself afterwards.

I feel like if I stick with meditation and keep it a part of my life that I will continue to learn more about being and living, resulting in a greater development of understanding for all the life around me, as well as my own.

These distinct reasons indicate the broad reach of the class and how each student chose to interpret meditation in their own meaningful way.

\section{Discussion}

The many well-researched and numerously cited benefits of meditation have prompted some educational researchers to call for a public-health oriented approach to bringing meditation to higher education. They reason that if mindfulness could be taught to all students, university educators might prevent the growth of mental health issues and stem the increasing demand for on-campus services (Parcover et al., 2015). Other researchers have argued that the best way to deliver meditation has not been fully investigated and more research is required before administrators would have a reason to create a standard curriculum (Hindman et al., 2015). In fact, the published research examining a mandatory mindfulness course found that many students were not interested and did not participate fully (Ching et al., 2015).

Undergraduates are just learning to think critically about their world, question assumptions and decide for themselves how to live their lives. Providing them an understanding of the cultural and historical forces that have brought mindfulness and meditation into contemporary life helps students understand a modern 'trend,' and offers them a number of ways to think about and pursue contemplative practice. It also allows them to take charge of their own engagement. "In 
my short meditation training in high school I never learned about the Dharma or Buddha's history," wrote one student. "It helped me to know how meditation began and what are its principles. That way I am not just following directions." Another student commented on how the contextual materials offered during the seminar changed his perspective. "The Dhamma Brothers...motivated me to take meditation more seriously... I suppose if a murderer can face his inner self silently for ten days, I should be able to handle it." A class structure that includes ten weeks of meditation practice provides students with significant understanding of their personal experience so they can decide for themselves if they want to continue. Making their own decisions is important to young adults, as this student made abundantly clear. "For me, meditation is a mindset. It's taking a second to breathe, not because the Buddha says we should or because a scientist says it'll help, but because I know I need that break."

Teaching meditation in a cultural and historical context creates a broad orientation that is inclusive of a diversity of students and addresses their multiple reasons for taking the seminar. The class described in this article includes contemplative practices that address students' concerns with the stress of undergraduate life and provides them relief from the overwhelming demands. The framework presents a view of multiple forms of the Dharma that were understandable to those students raised in Buddhist households or "heritage traditions" and those students who may have a parent who practices meditation as part of a "meditation-based convert lineage." Buddhist communities in the US are widely distinctive in the traditions they follow and the practices they teach, a fact that a number of scholars have recently articulated (McMahan, 2008; Gleig, 2019).

Situating meditation and contemplative practices historically also allows educators to communicate in ways that address many of the issues raised by academics working in neuroscience, psychology, and Asian and Buddhist studies. These scholars are not opposed to teaching a practice that has the potential to relieve suffering, yet they have expressed a variety of concerns about the teaching of mindfulness without a context. Some note that the use of self-reporting scales may cause unintentional harm to the development of mindfulness-based interventions through a denaturing and distorting of the very meaning of mindful awareness (Huntington, 2015; Stuart, 2017). Others point out the great variation regarding the meaning of mindfulness and the fact that there is no consensus on description (Van Dam et al., 2018). The fundamental concern is that the full depth of well-being that meditation practice has to offer will not be incorporated into Western psychology without coming to terms with what mindfulness means within the Buddhist tradition. As one scholar argues, in referring to the scales that measure mindfulness as a 'trait,' it may be that 'mindfulness is not a 'construct' as we traditionally understand it in Western psychology, but at depth, a way of being." (Grossman \& Van Dam, 2011). Other scholars have presented broader critiques and contend that when mindfulness is severed from its ethical traditions it becomes a tool for self-centeredness and self-absorption, characteristics that reinforce the neoliberal status quo (Forbes, 2019; Purser, 2019).

This analysis of teaching methodology suggests that students benefit when contemplative practices are presented in a wide context that promotes curiosity, engagement and persistence. An intentional and systematic research project that would provide more substantive data could confirm these insights and a longitudinal study that addressed the implicit results of the study would be useful. The seminar was an academic course offered for credit and participants received a pass or no pass, not a grade. Students were encouraged to report their experiences honestly in order to get instructor feedback, but some may have been inclined to write what they thought was expected of them. The narrative self-reports from the nine-year teaching record of "Contemporary American Buddhism" contained a rich ethnographic record, but more highly structured interviews could also provide more insight on how to present contemplative practice to college age students. Of primary importance would be understanding if offering meditation instruction within the historical and cultural context is what helps to sustain student interest in meditation and how that, in turn, affects mental health and academic success. A future study could make use of a mental health instrument and also collect demographic information on gender, age, and county of origin, as well as information as to whether the student was first generation, freshman or transfer student. This information could inform any resulting educational guidelines that were based on the research.

\section{Conclusions}

The purpose of this qualitative analysis was to assess the teaching methods employed in presenting the seminar "Contemporary American Buddhism." An examination of nine years of student self-reports and reflections indicate that students had beneficial experiences similar to those reported with studies using MBSR and other highly structured protocols. The curriculum and teaching methods employed also offered students historical and cultural context that provided an intellectual understanding and promoted choice and a sense of agency, two values important to young adults. Given the interest in bringing contemplative practices to college campuses, it is important to understand different pedagogical approaches and methodologies and this article adds to the growing research in this area. 
Data Availability N/A.

Code Availability N/A.

\section{Declarations}

Conflict of Interest The author declares that they have no conflict of interest.

Ethics Approval This is a study of the author's teaching method with meditation and mindfulness. Students regularly assessed their meditation experiences and shared these with the class and publicly.

Informed Consent Students were informed that classroom materials were a part of a study on teaching methods and their comments and reflections might appear in a publication.

Open Access This article is licensed under a Creative Commons Attribution 4.0 International License, which permits use, sharing, adaptation, distribution and reproduction in any medium or format, as long as you give appropriate credit to the original author(s) and the source, provide a link to the Creative Commons licence, and indicate if changes were made. The images or other third party material in this article are included in the article's Creative Commons licence, unless indicated otherwise in a credit line to the material. If material is not included in the article's Creative Commons licence and your intended use is not permitted by statutory regulation or exceeds the permitted use, you will need to obtain permission directly from the copyright holder. To view a copy of this licence, visit http://creativecommons.org/licenses/by/4.0/.

\section{References}

Astin, J. A. (1997). Stress reduction through mindfulness meditation. Psychotherapy and Psychosomatics, 66, 97-106

Baer, R. A. (2003). Mindfulness training as a clinical intervention: A conceptual and empirical review. Clinical Psychology: Science and Practice, 10, 125-143. https://doi.org/10.1093/clipsy/bpg015

Baer, R. A., Smith, G. T., \& Allen, K. B. (2004). Assessment of mindfulness by self-report: The Kentucky inventory of mindfulness skills. Assessment, 11(3), 191-206. https://doi.org/10.1177/10731 91104268029

Baer, R. A., Smith, G. T., Hopkins, J., Krietemeyer, J., \& Toney, L. (2006). Using self-report assessment methods to explore facets of mindfulness. Assessment, 13(1), 27-45. https://doi.org/10.1177/ 1073191105283504

Bamber, M. D., \& Schneider, J. K. (2016). Mindfulness-based meditation to decrease stress and anxiety in college students: A narrative synthesis of the research. Educational Research Review, 18, 1-32. https://doi.org/10.1016/j.edurev.2015.12.004

Baratz, N. (Director). (2009). Unmistaken Child. [Motion picture]. Oscilloscope

Beddoe, A. E., \& Murphy, S. O. (2004). Does mindfulness decrease stress and foster empathy among nursing students? Journal of Nursing Education, 43(7). https://doi.org/10.3928/0148483420040701-07

Bergen-Cico, D., Possemato, K., \& Cheon, S. (2013). Examining the efficacy of a brief mindfulness-based stress reduction (Brief MBSR) program on psychological health. Journal of American College Health, 61(6), 348-360. https://doi.org/10.1080/07448 481.2013.813853
Britton, W. B., Brown, A., Kaplan, C. T., Goldman, R. E., DeLuca, M., Rojiani, R. ... Frank, T. (2013). Contemplative Science: An Insider Prospectus. New Directions for Teaching and Learning. No. 134. https://doi.org/10.1002/tl.20051

Brown, K. W., \& Ryan, R. M. (2003). The benefits of being present: Mindfulness and its role in psychological well-being. Journal of Personality and Social Psychology, 84(4), 822. https://doi.org/10. 1037/0022-3514.84.4.822

Brown, K. W., Ryan, R. M., \& Creswell, J. D. (2007). Mindfulness: Theoretical foundations and evidence for its salutary effects. Psychological Inquiry, 18(4), 211-237

Bush, M. (2011). Mindfulness in higher education. Contemporary Buddhism, 12(1),183-197. https://doi.org/10.1080/14639947.2011. 564838

Canby, N. K., Cameron, I. M., Calhoun, A. T., \& Buchanan, G. M. (2015). A brief mindfulness intervention for healthy college students and its effects on psychological distress, selfcontrol, meta-mood, and subjective vitality. Mindfulness, 6(5), 1071-1081

Carmody, J., Reed, G., Kristeller, J., \& Merriam, P. (2008). Mindfulness, spirituality and health-related symptoms. Journal of Psychosomatic Research, 64, 393-403. https://doi.org/10.1016/j.jpsyc hores.2007.06.015

Cavanagh, K., Strauss, C., Cicconi, F., Griffiths, N., Wyper, A., \& Jones, F. (2013). A randomized controlled trial of a brief online mindfulness-based intervention. Behavior Research and Therapy, 51(9), 573-578

Center for Collegiate Mental Health (2018). 2017 Annual Report. Publication No. STA 18-166

Ching, H., Koo, M., Tsung-Huang, T., \& Chen, C. (2015). Effects of a mindfulness meditation course on learning and cognitive performance among university students in Taiwan. Evidence Based Complementary and Alternative Medicine. 2015. https://doi.org/ $10.1155 / 2015 / 254358$

Clarke, A. (2005). Situational analysis: Grounded theory after the postmodern turn. Sage Publications

Culham, T. E. (2013). Ethics education of business leaders: Emotional intelligence, virtues, and contemplative learning. Information Age Publishing

Davidson, R. J., \& Kaszniak, A. W. (2015). Conceptual and methodological issues in research on mindfulness and meditation. American Psychologist, 70(7), 581-592

Forbes, D. (2019). Mindfulness and its discontents: Education, self and social transformation. Halifax \& Winnipeg. Fernwood Publishing

Glaser, B. G., \& Strauss, A. L. (1967). The discovery of grounded theory: Strategies for qualitative research. Aldine Publishing Company

Gleig, A. (2019). American dharma: Buddhism beyond modernity. Yale University Press

Gockel, A., \& Deng, X. (2016). Mindfulness training as social work pedagogy: Exploring benefits, challenges, and issues for consideration in integrating mindfulness into social work education. Journal of Religion \& Spirituality in Social Work: Social Thought, 35(3), 222-244. https://doi.org/10.1080/15426432.2016.1187106

Grossman, P., \& Van Dam, N. T. (2011). Mindfulness, by any other name... trials and tribulations of sati in western psychology and science. Contemporary Buddhism, 12(1), https://doi.org/10.1080/ 14639947.2011.564841

Hindman, R. K., Glass, C. R., Arnkoff, D. B., \& Maron, D. D. (2015). A comparison of formal and informal mindfulness programs for stress reduction in university students. Mindfulness, 6(4), 873-884

Huntington, C. W., Jr. (2015). The triumph of narcissism: Theravada Buddhist meditation in the marketplace. Journal of the American Academy of Religion, 83(3), 624-648. https://doi.org/10.1093/ jaarel/lfv008 
Ingram, C. M., Breen, A. V., \& van Rhijn, T. (2017). Teaching for wellbeing? Introducing mindfulness in an undergraduate course. Journal of Further and Higher Education. https://doi.org/10.1080/ 0309877X.2017.1409343

Kabat-Zinn, J. (1982). An outpatient program in behavioral medicine for chronic pain patients based on the practice of mindfulness meditation: Theoretical considerations and preliminary results. General Hospital Psychiatry, 4, 33-47

Kabat-Zinn, J. (2003). Mindfulness-Based interventions in context: Past, present and future. Clinical Psychology:Science and Practice, 10, 144-156. https://doi.org/10.1093/clipsy/bpg016

la Cour, P., \& Petersen, M. (2015). Effects of mindfulness meditation on chronic pain: A randomized controlled trial. Pain Medicine, 16(4), 641-652. https://doi.org/10.1111/pme.12605

Lindahl, J. R., Fisher, N. E., Cooper, D. J., Rosen, R. K., \& Britton, W. B. (2017). The varieties of contemplative experience: A mixedmethods study of meditation-related challenges in Western Buddhists. PLoS ONE, 12(5), https://doi.org/10.1371/journal.pone. 0176239

Lutz, A., Slagter, H. A., Dunne, J. D., \& Davidson, R. J. (2008). Attention regulation and monitoring in meditation. Trends in Cognitive Science, 12(4)

Malpass, A., Binnie, K., \& Robson, L. (2019). Medical students' experience of mindfulness training in the UK: Well-being, coping reserve, and professional development. Education Research International, 2019. https://doi.org/10.1155/2019/4021729

McMahan, D. L. (2008). The making of Buddhist modernism. Oxford University Press, Inc

Miller, C. J., Borsatto, J., \& Al-Salom, P. (2018). Testing a quick mindfulness intervention in the university classroom. Journal of Further and Higher Education. https://doi.org/10.1080/0309877X. 2017.1409345

Newsome, S., Waldo, M., \& Gruszka, C. (2012). Mindfulness group work: Preventing stress and increasing self-compassion among helping professionals in training. The Journal for Specialists in Group Work, 37(4), 297-311. https://doi.org/10.1080/01933922. 2012.690832

Parcover, J., Coiro, M. J., Finglass, E., \& Barr, E. (2018). Effects of a brief mindfulness-based group intervention on college students. Journal of College Student Psychotherapy, 32(4), 312-329. https://doi.org/10.1080/87568225.2017.1407722

Parcover, J., Mays, S., \& McCarthy, A. (2015). Implementing a public health approach to addressing mental health needs in university settings: Lessons and challenges. Journal of College Student Psychotherapy, 29, 197-210. https://doi.org/10.1080/87568225.2015. 1045781

Parker, J. D. A., Summerfeldt, L. J., Hogan, M. J., \& Majeski, S. A. (2004). Emotional Intelligence and academic success: examining the transition from high school to university. Personality and Individual Differences, 36(1), 163-172

Petitmengin, C., Van Beek, M., Bitbol, M., Nissou, J., \& Roepstorff, A. (2017). What is it like to meditate? Methods and issues of a microphenomenological description of meditative experience. Journal of Consciousness Studies, Imprint Academic, 24(5-6), 170-198

Phillips, J., Kukura, A., \& Stein, A. M. (Directors) (Eds.). (2007). The Dhamma Brothers. [Motion picture]. Bullfrog Films
Purser, R. (2019). McMindfulness: How mindfulness became the new capitalist spirituality. London: Repeater Books

Ramsberg, J. T., \& Youmans, R. J. (2014). Meditation in the highereducation classroom: meditation training improves student knowledge retention during lectures. Mindfulness, 5(4), 431-441

Riskin, L. (2012). Awareness and the legal profession: An introduction to the mindful lawyer symposium. Journal of Legal Education, 61(4), 634-640

Schwind, J. K., McCay, E., Beanlands, H., Martin, S., Martin, L., \& Binder, M. (2016). Mindfulness practice as a teaching-learning strategy in higher education: A qualitative exploratory pilot study. Nurse Education Today, 50, 92-96. https://doi.org/10.1016/j.nedt. 2016.12.017

Scida, E. E., \& Jones, J. N. (2017). Navigating stress: Graduate student experiences with contemplative practices in a foreign language teacher education course. The Journal of Contemplative Inquiry, 4(1), 207-228.

Selye, H. (1984). The stress of life. McGraw-Hill Education.

Short, M. M., Mazmanian, D., Ozen, L. J., \& Bédard, M. (2015). Four days of mindfulness meditation training for graduate students: A pilot study examining effects on mindfulness, self-regulation, and executive function. The Journal of Contemplative Inquiry, 2(1), 37-48.

Stuart, D. M. (2017). Insight transformed: Coming to terms with mindfulness in South Asian and global frames. Religions of South Asia, $11,2-3$

Trail, J., \& Cunningham, T. (2018). The Compassionate University: How University of Virginia is Changing the Culture of Compassion at a Large, American Public University. Journal of Perspectives in Applied Academic Practice, 6(3)

Van den Hurk, P. A. M., Giommi, F., Gielen, S. C., Speckens, A. E. M., \& Barendregt, H. P. (2010). Greater efficiency in attentional processing related to mindfulness meditation. Quarterly Journal of Experimental Psychology, 63(6), 1168-1180. https://doi.org/ 10.1080/17470210903249365

Van Dam, N. T., van Vugt, M. K., Vago, D. R., Schmalzl, L., Saron, C. D., Olendzki, A., \& Meyer, D. E. (2018). Mind the hype: A critical evaluation and prescriptive agenda for research on mindfulness and meditation. Perspectives on Psychological Science, 13(1), 36-61

Van der Riet, P., Rossiter, R., Kirby, D., Dluzewska, T., \& Harmon, C. (2015). Piloting a stress management and mindfulness program for undergraduate nursing students: Student feedback and lessons learned. Nurse Education Today, 35, 44-29. https://doi.org/10. 1016/j.nedt.2014.05.003

Wolcott, F. (2013). On contemplation in mathematics. Journal of Humanistic Mathematics, 3(1), 74-95

Würtzen, H., Dalton, S. O., Elsass, P., Sumbundu, A. D., StedingJensen, M., Karlsen, R. V. ... Johansen, C. (2013). Mindfulness significantly reduces self-reported levels of anxiety and depression: Results of a randomized controlled trial among 336 Danish women treated for stage I-III breast cancer. European Journal of Cancer, 49(6), 1365-1373. https://doi.org/10.1016/j.ejca.2012. 10.030

Publisher's Note Springer Nature remains neutral with regard to jurisdictional claims in published maps and institutional affiliations. 